CEREBRAL CiRCULATION AND METABOLISM. Thomas W. LaNGfitT, lawrence C. MCHenry Jr., Martin Reivich e HaRry Wollman, editores. Um volume com 566 páginas, Springer Verlag, Berlim-Heidelberg-New York, 1975.

Este livro contém os relatórios apresentados ao VI Simpósio Internacional sobre Fluxo Sangüineo Cerebral, realizado em Filadelfia entre 6 e 9 de junho de 1973. Atenção especial fol focalizada no controle neurogênico da circulação e do metabolismo cerebrais, constituindo matéria de três sessões do congresso. Considerações sobre a metodologia para a medição do fluxo sangüineo cerebral e decorrências dos respectivos resultados foram objeto de outras duas sessôes. Interesse especial mereceram também as aplicaçōes clínicas dos diversos métodos, principalmente no que concerne a traumatismos cranianos, doenças vasculares cerebrais, crises convulsivas, tumores intracranianos, doenças infecciosas e perturbações mentais. Em várias sessões adicionais foram considerados os efeitos experimentais do edema e da isquemia cerebrais e dos traumatismos cranianos. Finalmente, foram discutidos os efeitos de agentes farmacológicos sobre o fluxo sangüíneo e metabolismo cerebral. Os diversos relatórios que compunham cada sessão, foram reunidos em outros tantos capitulos, que eram encerrados por apreciações sintéticas de especialistas previamente convidados.

No que concerne a auto-regulação, as várias comunicações confirmaram seus conceitos correntes sem trazer qualquer modificação radical. Novos dados vieram demonstrar, contudo, uma acentuada capacidade de auto-regulação em diferentes espécies, sujeita, no entanto, a uma fácil abolição, assim como uma aparente função, dessa auto-regulação, na conservação de um fluxo capilar constante. Os limites da auto-regulacão dependiam, segundo foi demonstrado, do modo segundo o qual a pressão de perfusāo fora modificada. De qualquer forma, o quadro de auto-regulação parece ser complexo e seu mecanismo ainda não é perfeitamente conhecido. A explicação, até o momento mals plausivel, reside em um efeito miogênico básico ao qual efeitos metabólicos e neurogênicos podem estar superpostos. No referente ao controle químico da circulação encefálica, merecem ser mencionadas as conclusões que demonstram o papel vaso-dilatador preponderante do potássio, quando seu teor no fluído extracelular aumenta ligeiramente. Parece comprovado que o potássio assumiu o principal papel como metabólico vaso-dilatador local, quer em condições de hipóxia, quer em atividade neuronal. Um tópico de interesse particular é o fenômeno da falta de um refluxo, decorrente da lesão vascular pela isquemia difusa. Segundo opiniões muito categorizadas, parece haver dificuldade na re-instituição de um fluxo normal, através de vasos cerebrais, após periodos relativamente curtos de estase completa. Esse comprometimento resulta, em parte, de um aumento da viscosidade sangüínea e, talvez, também de um estreitamento da luz capilar. Cerca de 7,30 minutos, após seu aparecimento, pode contribuir para a morte da célula parenquimatosa. Trabalhos extensivos sobre a metodologia da medida do fluxo sangüíneo cerebral regional, por processos invasivos e não invasivos, complementam esta importante obra cuja leitura, ou consulta, consideramos indispensável para os estudiosos do assunto. 
ADVANCES IN NEUROLOGY. WALTER J. FRIEdLANDER, editor. Um volume encadernado (16,5x24) com 392 páginas e 30 ilustrações. Volume 13 da coletânea Current Reviews. Raven Press, New York, N. Y. 1975.

O alvo visado na compilação do material e na elaboração deste ljvro consistiu na análise critica de elementos básicos colhidos, em sua maioria, em laboratórios de alto gabarito científico mediante pesquisas de caráter experimental, selecionando o que existe de mais atualizado e mais acertado para oferecer aos neurologistas toda uma gama de dados publicados em revistas especializadas, nem sempre ao seu alcance direto. Essencialmente o editor procurou reunir revisões da literatura para atender aos anseios dos clínicos no sentido de atualizar seus conhecimentos à luz de pesquisas laboratoriais refinadas, fornecendo, mediante extensas e minuciosas consultas ao que já está registrado, e pela palavra de cientistas de alto valor, os elementos para o diagnóstico, para a terapêutica racional e para o prognóstico de algumas afeç̧óes neurológicas. Os assuntos escolhidos para constituir os 7 capítulos deste livro são dos mais atualizados, abrangendo importantes setores da prática da Neurologia.

No primeiro, Richard T. Johnson estuda a Possivel etiologia viral da esclerose múltipla (46 páginas e 252 citações bibliográficas) e depois de revisar o que foi registrado no tocante à etiologia dessa grande incógnita que ainda é a esclerose múltipla, analisa os fatos e as pesquisas que levam a pensar na ação de viros, especialmente de ação lenta e retardada, na patogenia da desmielinização. De grande atualidade é a revisão feita por 'William J. Logan sobre os Aspectos neurológicos das drogas alu. cinógenas (32 páginas e 303 referências bibliográficas). De suma importância dado o amplo interesse pelo assunto é o capitulo seguinte no qual $\mathrm{E}$. W. Maynert, T. J. Marczinski e R. A. Browing revisam o Papel dos neurotransmissores nas epilepsias (69 páginas e 402 citações bibliográficas), analisando minuciosamente a farmacologia e a farmacodinamia das substâncias excitadoras e inibidoras dos impulsos epileptógenos. No capitulo IV Michael D .Walker e Horward D. Weiss analisam os resultados da Quemoterapia no tratamento dos tumores cerebrais malígnos (44 páginas e 151 citacões bibliográficas), comparando os efeitos das drogas mais utilizadas sobre os diferentes tipos de neoplasias e indicando os melhores momentos e condições para sua aplicação. Muito útil do ponto de vista prático é a revisão que Miron Winick fez dos Efeitos da malnutrição na maturação do sistema nervoso central (55 páginas e 190 citações bibliográficas) mostrando que, do ponto de vista humanitário, esta área de estudos merece ação urgente por parte dos neurologistas. A seguir, em capitulo amplamente ilustrado, Keasley Welch revisa, analisando e criticando, tudo o que tem sido escrito sobre os Principios da fisiologia do liquido cefalorraqueano em relaçāo com o hidrocéfalo, incluindo o hidrocéfalo com pressão normal (86 páginas e 439 citaçōes bibliográficas). No último capitulo Manuchair Ebadi condensa, em excelente apanhado geral, o estudo das Bases farmacocinéticas da terapêutica médica com especial referência aos medicamentos usados em Neurologia (48 páginas e 168 citações bibliográficas). Bem condicionado indice final facilita a consulta rápida aos itens tratados neste livro que deve ser lido no seu todo pois se trata de contribuição valiosa aos 14 volumes já editados da coletânea "Advances in Neurology Series", todos visando ao entrosamento das ciências básicas com a Neurologia Clínica para melhor compreensão dos distúrbios neurológicos, para o esclarecimento da etiopatogenia dos males que afetam o sistema nervoso e para racionalisar o aproveitamento dos recursos terapêuticos atualmente à disposição dos neurologistas.

\section{O. LANGE}

GROWTH AND DEVELOPMENT OF THE BRAIN: NUTRICIONAL, GENETIC AND ENVIRONMENTAL FACTORS. MARY A. B. BRAZIER, ed. Um volume encadernado com 413 páginas, 90 ilustrações e 38 tabelas. Volume 1 da série International Brain Research Organization Monographs. Raven Press, New York, 1975. 
Este livro injcia uma coleção a ser publicada pela International Brain Research Organization (IBRO) que divulgará as mais recentes aquisições das ciências neurológicas básicas hauridas em laboratórios especializados mediante pesquisas clínicas e experimentais. Este primeiro volume - crescimento e desenvolvimento do cérebro: fatores nutricionais, genéticos e ambientais - assim como o segundo da série Disfunção cerebral nas convulsões infantis febris - são eđitados por Mary A. B. Brazier, do Brain Institute Rechearch da Universidade da Califórnia, o que é uma garantia quanto à validade do conteúdo. O primeiro que temos em mãos contêm 22 trabalhos apresentados em simpósio realizado em Nova Delhi (fndia) em outubro de 1974, estudando aspectos diversos do desenvolvimento do cérebro, especiaimente correlacionados a fatores nutricionais, genéticos e ambientais, com o objetivo de atualizar conhecimentos básicos em matéria de anatomia, bioquímica, fisiologia e eletrofisiologia e de genética à luz dos fatores nutricionais e da ecologia. Simples menção dos diferentes capítulos dará idéia quanto ao valor deste livro para os que se dedicam ao estudo dos assuntos versados: Nutricão, crescimento e diferenciação celular; Ontogênese de alguns componentes celulares no cérebro em desenvolvimento no decorrer da maturação funcional; Morfogênese do cortex visual em crianças prematuras; Influências sensoriais na atividade das ATPases cerebrais; Aspectos neuroquimicos do crescimento e desenvolvimento do cérebro; Efeitos de fatores metabólicos no desenvolvimento cerebral; Ação androgênica perinatal e diferenciação do hipotálamo; Efeitos de deficiências nutritivas na composição e na atividade metabólica do cérebro; Desenvolvimento de conexões funcionais no sistema visual; Os ganglios basais e a regulacão do comportamento; Correlações bioquímicas e genéticas no determinismo do comportamento; Estudo genético da epilepsia com contribuição de diversos modelos especialmente os foto-sensitivos; Estudos da vocalização em macacos; Desenvolvimento da sinergia interhemisférica no EEG de crianças; $O$ EGG nos erros inatos do metabolismo; Malnutrição, desenvolvimento cerebral e comportamento; Influência da malnutrição protêica no desenvolvimento intelectual; Crescimento cerebral em crianças com malnutrição protêica; Correlação da malnutrição com o comportamento; Fatores que afetam o desenvolvimento psicológico. Como se depreende deste enunciado, alguns dados relatados neste livro são de suma importância e atualidade não só para médicos em geral como para pediatras, psiquiatras e neurologistas, e em particular para psicólogos. Aqueles que devem zelar pela correção ou prevencão dos danos determinados no cérebro pela malnutrição e pelos defeitos de alimentação encontrarão neste livro farto material para reflexão e, eventualmente, novas sendas para a pesquisa dos fatores nutricionais que diminuem a capacidade intelectual.

\section{O. LANGE}

COMPLEX PARTIAL SEIZURES AND THEIR TREATMENT. J. KIFFIN PENRY e DAVID D. DALY, editores. Um volume encadernado (16x24) com 486 páginas, 38 tabelas e 63 ilustrações. Volume 11 da coleção "Advances in Neurology", Raven Press Publishers, New York, 1975.

Este livro cuida de um dos mais proteiformes capitulos da Medicina, como seja o das crises epilépticas parciais e complexas, incluindo dados importantes para o diagnóstico, pormenorizando as múltiplas manifestações clínicas, salientando os modos de comportamento dos pacientes durante as crises e nos periodos intercríticos, expondo as anormalidades eletrencefalográficas mais encontradiças, enfatizando os elementos para o diagnóstico diferencial e para o prognóstico, fornecendo os últimos progressos no que diz respeito ao tratamento médico e cirúrgico. Estas doenças, depois das geniais considerações e tentativas de classificacão feitas por Hughlings Jackson no último quartel do século passado, cairam em relativo olvido e só voltaram à baila depois do advento da eletrencefalografia, e, principalmente, depois de descriçōes mi- 
nuciosas de corajosos e eminentes epileptólogos e dos resultados obtidos, seja pela introđução de novas medicações antiepilépticas seja pelos bons resultados obtidos por neurocirurgiōes mediante excisōes bem indicadas e perfeitamente justificadas no lobo temporal. Muita coisa tem sido escrita sobre este intrincado assunto e os editores deste livro visaram a atualizar os dados colhidos na literatura, aproveitados à luz da grande experiéncia dos autores que foram convidados para cooperar, no sentido de fornecer melhores possibilidades para o diagnóstico e apresentar o que há de melhor no tocante à terapêutica destas afecções que, situadas em terreno comum à Neurologia, à Psiquiatria e à Psicologia, constituem males de grande repercussão tanto para os pacientes como para seus familiares.

O livro contêm 23 trabalhos, todos de alto valor, como sejam: 1 - Perspectivas gerais nas crises parciais complexas (J. Kiffin Penry); 2 - Morfologia do lobo límbico (R. B. Chronister e L. E. White Jr.); 3 - Fisiologia do sistema do lobo límbico 4 - Manifestacōes clinicas ictais das crises parciais complexas (David D. Daly); 5 Manifestações clinicas interictais (Janice R. Stevens); 6 - Manifestaçós eletrencefalográficas (Donald W. Klass); 7 - Inicio e propagação dos fócos epileptógenos (Eli S. Goldensohn); 8 - Patologia focal do lobo temporal (Gordon Mathieson); 9 - Diagnóstico diferencial das crises parciais com sintomatologia complexa (F. E. Dreifuss). Os restantes capitulos, representando mais da metade do livro, dizem respeito à terapêutica e aos resultados até agora obtidos: 10 - Prognóstico e terapêtica das crises parciais complexas com barbitúricos, hidantoinas $e$ outros medicamentos (C. A. Tassinari e J. Roger); 11 - Tratamento de adultos com a carbamazepina (M. Parsonage); 12 - Tratamento de crianças com a carbamazepina (Ingrid Gamstorp); 13 - Química e métodos da determinação da carbamazepina (Henn Kutt); 14 - Mecanismos de ação da carbamazepina (R. M. Jullen e R. P. Hollister); 15 - Absorção, distribuição e excreção da carbamapezina (P. L. Morselli); 16 - Biotrasformacão da carbamazepina (A. Frigerio e P. L. Morselli); 17 - Concentração sangüinea da carbamazepina e controle clinico ( $\mathrm{J}$. J. Cereghino); 18 - Efeitos da carbamazepina no comportamento (M. A. Dalby); 19 - Neurotoxicidade da carbamazepina (E. H. Reynolds); 20 - Toxidez hematológica da carbamazepina (A. V. Pisciotta); $21-C u i-$ dados para os dificeis pacientes com crises crises parciais complexas (E. A. Rodin). Os trabalhos acima citados dizem respeito às possibilidades do tratamento médico, especialmente com a mais recente aquisição do arsenal terapêtico - a carbamazepina - que tem evidente ação benéfica em grande número de casos embora deva ser administrada cuidadosamente, sob controle médico rigoroso. No último capitulo deste valioso livro, à guisa de coroamento, encontra-se uma jóia propiciada por Theodore Rasmussen sobre o Tratamento cirúrgico de pacientes com crises epilépticas parciais completas, no qual o autor, com base em sua vasta e nutrida experiência, indica quais as condiçôes exigidas para o tratamento cirúrgico e quais as mais eficientes técnicas operatórias. Como se vê; este livro tem material para satisfazer, na atualidade, neurologistas, psiquiatras, psicólogos e clínicos gerais, estes últimos sendo na maioria dos casos os primeiros a serem consultados pelos pacientes e seus familiares. A inclusão, em cada capitulo, de referências bibliográficas pertinentes e das discussōes que os trabalhos provocaram quando foram apresentados em simpósios ou em congressos, aumenta o interesse pela leitura do livro. Bem elaborado indice remissivo final completa o volume e facilita sua utilização.

\section{O. LANGe:}

CLINICAL, MORPHOLOGIC AND NEUROCHEMICAL ASPECTS IN THE AGING CENTRAL NERVOUS SYSTEM HAROLD BLODY, DENHAM HARMAN e J. MARK ORDY, editores. Um volume encadernado (16×24) com 221 páginas, 14 tabelas e 69 ilustraçōes. Volume 1 da coleção "Aging”. Raven Press Publishers, New York, 1975.

A multiplicidade dos problemas determinados pelo envelhecimento do organismo humano, cuja freqüêrcia aumenta progressivamente em função do aumento de longevidade assinalado nas últimas décadas, levou a grande número de pesquisas ten- 
dentes a demonstrar quais as conseqüências diretas e, por assim dizer, fisiológicas da senectude, visando a diminuir, no que for possivel, sua intensidade e, assim, proporcionando aos individuos velhos maiores possibilidades de um viver normal ou, melhor, subnormal. Daí a idéia meritória de preparar uma coleção de livros especializados, todos com o mesmo alvo genérico, de mostrar as consequiências do envelhecimento em todos os aparelhos e setores do organismos humano. Esta nova coleção - AGING fol iniciada com este volume que trata precipuamente dos aspectos clínicos, morfológicos e neuroquímicos do envelhecimento do sistema nervoso central, realcando mais uma vez a importância da Neurologia no mundo das ciências médicas. O livro foi subdividido em 8 capitulos, todos de grande atualidade: 1 - Aspectos clinicos do envelhecimento do sistema nervoso central (Lissy F. Jarvik); 2 - Alteraçóes estruturais no cérebro envelhecido (Madge E. Scheibel e Arnold B. Scheibel); 3 - Acúmulo $e$ distribuição de lipofuscina, de amiloides $e$ de placas senis no sistema nervoso envelhecido (Kenneth R. Brizzee, James C. Harkin, J. Mark Ordy e Bernice Kaack); 4 Relacões histoquimicas e natureza da neuromelanina (Herbert Barden); 5 - Idade e lípides do sistema nervoso central (Govind A. Dhopeshwarkar e James F. Mead); 6 Alteracões neuroquimicas no decorrer da vida no cérebro humano (J. Mark Ordy, Bernice Kaack e Kenneth R. Brizzee); 7 - Múltiplas formas de monoamina oxidase e envelhecimento (Jean $\mathrm{C}$. Shih); 8 - Alterações nas aminas biogênicas cerebrais relacionadas com a idade (T. Samorajski). Cada capítulo é complementado com as respectivas referências bibliográficas para os que desejarem se aprofundar nos assuntos versados. Todos os médicos - os moços para saber o que devem analisar sintomatológicamente em seus pacientes idosos, e os velhos para saber as causas de seus enfraquecimentos no tocante a funçōes vitais tanto neurológicas como psiquicas - devem ler este livro que, desde a jlustração de capa, mostra as causas concretas, ou algumas das causas, das dificuldades inerentes ao envelhecimento.

O. LANGE

LA PHARMACODÉPENDENCE. J. F. KRAMer e D. C. Cameron. Opúsculo com 112 páginas. Editado pela Organização Mundial de Saúde, 1975. Publicado em francês, inglês e espanhol. A venda na Biblioteca Regional de Medicina OMS/OPS, Caixa Postal 20381, 01000 São Paulo SP, Brasil.

Desde sua fundacão, em 1945, a Organização Mundial de Saúde coopera ativamente com a Organização das Nações Unidas para submeter a um controle internacional as substâncias que engendram dependência e cuja utilização cria ou pode criar problemas de saúde pública. Os pontos de vista expendidos por peritos conselheiros da OMS foram publicados no decurso de 30 anos em diferentes relatórios. $O$ opúsculo agora editado, a pedido da Fundação das Nações para a Luta contra o Abuso de Drogas, resume, comenta e atualiza esses vários relatórios. Nele será encontrado um resumo dos conhecimentos científicos sobre os problemas determinados pelas drogas, assim como descrições sobre os modos de utilização tradicionais e modernos dos diferentes tipos de dependēncia, de certas síndromes clinicas associadas ao uso de drogas, as circunstâncias de utilização, as características associadas à idade, as atitudes e as reações sociais correspondentes, sendo enfatizados os problemas humanos criados pela utilização de substâncias que engendram dependência. Certos problemas de pesquisa são mencionados e comentados. Referências finais indicam as publicações que serviram de base para a elaboração do apúsculo e referem os títulos de algumas outras obras dignas de consulta. Assim, este opissculo é destinado a guiar os que trabalham nos setores de saúde e bem-estar social e outras pessoas cujas profissões as levam a participar das açōes tendentes à diminuição da amplitude dos problemas sanitários e sociais determinados pelo uso e abuso, para fins não-médicos, de substâncias causadoras de dependência. 